\title{
Hacia una ciencia de la vida mental
}

\author{
Entrevista de Renaud Persiaux a \\ Stanislas Dehaene* \\ DOI: 10.22395/csye.v5n10a11
}

Su lección inaugural en el Colegio de Francia se tituló "Hacia una ciencia de la vida mental". ¿Por qué?

Primero, para inscribir mi proceder en la (ya) larga historia de la psicología; es la definición propuesta en el siglo XIX por William James, uno de sus padres fundadores. Segundo, porque yo creo que la psicología será uno de los nudos esenciales de una futura ciencia de la vida mental. Pluridisciplinaria, tendrá por objetivo explicar cómo pensamos por medio de series de leyes sucesivas, que tienen en cuenta diferentes aspectos de la biología del cerebro a la dimensión cultural. El reto es llegar a establecer leyes de la psicología tan universales como las de la física. Para mí, el pensamiento, aunque sea subjetivo e íntimo, puede ser estudiado de manera científica, especialmente porque sus características son ampliamente compartidas a través del mundo. Creo que cada una de nuestras representaciones mentales es también un objeto neuronal, incluso si las leyes de enlace entre los dos niveles todavía están por establecer. En el laboratorio, nuestras investigaciones se articulan ya entre comportamiento, desarrollo del niño, neuropsicología, imagenografía cerebral...

\section{¿Este proceder no es reduccionista por naturaleza?}

No. No soy de los que propone, como la filósofa Patricia Churchland, una neurociencia eliminativista en la que la psicología desaparecería en provecho de una neurociencia pura que reduce todos los objetos a la biología. A la inversa, pienso que existen leyes de la psicología en tanto que tales, completamente válidas en su nivel, al mismo título que las leyes de la lingüística y de la economía. Hay numerosos niveles de descripción de la extraordinaria complejidad del ser humano. Entre mejor se haya comprendido el nivel psicológico, más fácil será investigar sus bases neuronales.

\footnotetext{
Tomado de Jean-François Dortier (dir.). El cerebro y el pensamiento. La nueva edad de las ciencias cognitivas. Auxerre: Sciences Humaines éditions, 2014 (ed. revisada y aumentada del libro de 2012). pp. 53-58. Traducción del francés al español de Luis Alfonso Palau Castaño, Medellín, noviembre 15 de 2016.

Stanislas Dehaene es profesor de psicología cognitiva experimental del Collège de France. Director de la unidad de neuro-imagenología cognitiva Neurospin. Gran premio del Inserm 2013.
} 
Inversamente, los descubrimientos sobre el cerebro entrañan nuevas cuestiones de orden psicológico y nuevas teorías. Creo mucho en la interactividad entre las dos disciplinas.

La psicología funcionalista planteaba que cualquier programa puede ser efectuado por el cerebro, de la misma manera que cualquier logicial puede funcionar sobre el soporte material del ordenador. ¿Por qué rechaza usted esta concepción?

Esta metáfora del cerebro computador, que se inspira y mantiene una dicotomía artificial muy rígida entre cerebro y pensamiento, es extremadamente limitada. De ninguna manera el cerebro funciona así; la mayor parte de las operaciones mentales reposan sobre redes cerebrales especializadas (para percibir las formas o los colores, por ejemplo). Mis investigaciones y las de mi esposa Ghislaine Dehaene-Lambertz han mostrado que existen estructuras cerebrales organizadas para tratar el lenguaje hablado, ya presentes en el bebé de dos meses. Por ejemplo, el área de Broca se activa, en relación con otras regiones temporales, cuando el niño escucha frases en su lengua materna.

Y, sin embargo, usted no parece favorable a la noción de módulo innato...

No me gusta el término "innato", que no le hace justicia a la complejidad de las relaciones entre biología y psicología. Ciertamente, existen estructuras precoces en el cerebro. Y, sin embargo, no son "módulos" listos para ser empleados en el reconocimiento de rostros o en la lectura. Por el contrario, ellas maduran en la interacción con el entorno. Cuando, por ejemplo, usted estudia los circuitos cerebrales de la lectura a través del mundo, ya sea que se utilice escritura alfabética o ideogramas, siempre son las mismas zonas las que se activan. La plasticidad del cerebro deja el sitio a la variable cultural.

En su obra hay un término que regresa a menudo, el de código neural. ¿De qué se trata?

El código neural permite poner en relación las representaciones mentales y las neuronales. De hecho, no hay un código único sino muchos, diferentes según las regiones. Tomemos el ejemplo de la lectura. La codificación arranca desde la retina con algunos millones de fotorreceptores que detectan la presencia de luz en un punto dado. A partir de esa expansión, el cerebro logra reconstituir una representación de la palabra. ¿Cómo? Se piensa que interviene una jerarquía de representaciones visuales sucesivas. Se sabe que en el animal y en el hombre, existen tales jerarquías, por ejemplo, para el reconocimiento de los rostros. Algunas neuronas responden a una persona dada, a veces con un importante nivel de abstracción. Investigadores de San Diego han identificado, por ejemplo, una neurona que codifica para la star de Hollywood Jennifer Aniston, ya se la 
vea de frente, de perfil, o de espaldas, que se escuche su voz o su nombre. No es una neurona única la que hace el trabajo, sino millones, incluso si la tecnología utilizada -el registro celular- solo permite detectar una a la vez. Se trata pues de una asamblea neuronal "Jennifer Aniston", constituida por aprendizaje y distribuida en numerosas regiones cerebrales, cada una aportando su granito de arena a una etapa precisa del reconocimiento visual.

\section{¿Cómo se puede comprender ese código?}

Una herramienta muy útil es la imagenografía por resonancia magnética (IRM) que utilizamos, por ejemplo, para comprender la lectura. Lo que es apasionante es que los resultados que de allí salen concuerdan con las observaciones del neurólogo Jules Déjerine del siglo XIX, que trabajaba con sujetos que padecían lesiones cerebrales. Las áreas que faltaban en los pacientes aléxicos son precisamente las que se activan con la lectura. A medida que comprendemos la codificación neural de los objetos mentales, nos volvemos capaces de invertir el procedimiento; partiendo de la actividad cerebral tratamos de deducir el contenido mental. De este modo, Bertrand Thirion y yo hemos mostrado que, cuando uno imagina una letra (por ejemplo, una X), la topografía de la activación en las áreas visuales reproduce la forma de esa letra. Pero si hacemos el camino inverso, si se parte de esta activación, se puede deducir el stimulus que imaginó el sujeto. Evidentemente que hay numerosos límites; debido incluso a la débil resolución actual, el método solo funciona para las configuraciones macroscópicas de actividad. Se puede, por ejemplo, distinguir la percepción de un rostro de la de una casa, pues los territorios corticales que corresponden están distantes, al menos, en un centímetro. Pero por el momento, como no se ha entrado aún en las regiones, no se puede ver la diferencia entre la palabra "casa" y la palabra "rostro".

\section{¿La ciencia alcanza la ficción! ¿Sería posible leer en los pensamientos?}

En teoría, no encuentro argumento que se le pudiera oponer. Pero en la práctica, se requerirían unos productores de imágenes muchos más robustos que los que sabemos fabricar, y, por supuesto, un sujeto que colabore y permanezca perfectamente inmóvil. No necesitamos pues fantasmear; ningún Big Brother a la vista. De todas maneras leer los pensamientos no es lo que nos interesa. Buscamos solamente comprender los mecanismos del pensamiento, la manera como las áreas se articulan, como circula la información. Encontrar una ley de enlace psiconeuronal podría permitir, por ejemplo, comprender mejor el estado de los pacientes en coma, y mejorar su forma de cuidarlos. O también, detectando con la ayuda de electrodos cerebrales las intenciones de un sujeto, traducirlas en comandos efectivos, por ejemplo, para dirigir prótesis. Es una inmensa esperanza para los tetrapléjicos y los pacientes locked-in (literalmente los "encerrados en 
ellos mismos") que no pueden ni hablar ni hacer el menor gesto. La plasticidad cerebral permite a los pacientes adaptar su código neural a la máquina. A fines de 2006 fueron implantados los primeros brazos biónicos comandados por el cerebro, a un antiguo combatiente norteamericano.

Escuchándolo se da uno cuenta del gran aporte de la imagenología. ¿No se corre el riesgo de que ella se vuelva más importante que la psicología?

Absolutamente no; la psicología sigue siendo central. En mi laboratorio, son psicólogos los que definen todos los experimentos, para obtener las condiciones de estimulaciones más puras posibles y acceder así a los procesos elementales del pensamiento. La imagenografía cerebral y los otros métodos salidos de la física o de las neurociencias solo son para nosotros herramientas, aunque cruciales. Y creo que los laboratorios de psicología que no posean estas máquinas se van a ver en dificultades. En el centro Neurospin muy posiblemente desarrollaremos convenios y acogeremos experimentos externos.

¿Qué lo motiva para la fabricación de sus modelos psicológicos?

A mi manera de ver, la modelización debe jugar un rol esencial en psicología, a la vez para formular sus famosas leyes de establecimiento de los enlaces psiconeuronales, y para expresarlos bajo forma rigurosa, informática o matemática. Sin embargo, sigue siendo difícil desarrollar grandes teorías explicativas en psicología. Los modelos que he propuesto son más bien minimalistas, capaces de explicar una o algunas tareas psicológicas clásicas. Se basan en tres puntos: a) parten de una organización de neuronas reales, b) teniendo en cuenta la arquitectura del cerebro real, y c) simulando una verdadera tarea; se pone así en conexión el modelo con los datos empíricos. Estos modelos se parecen, pero solamente en parte, al conexionismo que, en los años 1980, constituía ya una interesante tentativa de modelización minimalista de la psicología. Si esta esperanza se perdió fue, en parte, a causa de la ausencia de una conexión con la realidad biológica. En la actualidad, es una verdadera biología teórica en dirección a la psicología la que desarrollamos, que integra auténticas propiedades neuronales.

Encuentro muy excitante el momento en que nuestros diferentes conocimientos coagulan en la forma de una teoría unificada. Por ejemplo, se constituye actualmente una "ciencia de la lectura" que comienza a explicar cómo aprendemos a leer, qué redes están implicadas y por qué el "método global" no funciona.

Piensa usted, como Jean-Pierre Changeux, que hay una "compatibilidad total entre el determinismo más absoluto y la aparente imprevisibilidad de nuestros comportamientos"... 
Incluso si pudiéramos disecarlos, nuestros mecanismos cerebrales son suficientemente complejos como para que sus resultados conserven un carácter no calculable y no previsible. Era un poco la idea de Baruch Spinoza cuando decía que los hombres se creían libres porque tenían conciencia de sus acciones, pero ignorantes de las causas que los determinan. Debemos aceptar que somos magníficas maquinitas. Y que, incluso, si nuestro comportamiento está determinado, no podemos preverlo. Me parece que, en la comparación del hombre con la máquina, no es el hombre el que sale disminuido, sino ila máquina la que sale engrandecida! Apenas comenzamos a comprender de qué es capaz una máquina neuronal, masivamente paralela y dotada de aprendizaje. Estos conocimientos tendrán numerosas repercusiones en informática y en la concepción de sistemas artificiales que nos ayudarán a superar los límites del cerebro humano.

Usted compara la psicología con la física de los años 1930... ¿Por qué?

Nuestra disciplina está en plena expansión, como la física en aquella época. Es un mundo nuevo el que se abre. La psicología, en el ámbito internacional, está en un período de creatividad y de exploración extraordinarias, con numerosos puentes lanzados en todos los sentidos -hacia las neurociencias pero también hacia la economía, la física, las matemáticas...-. Este carácter pluridisciplinario, y que lo abarca todo, a veces es un poco desconcertante; se requiere lograr mantener una coherencia. De alguna manera es una especie de i"edad heroica"!

Entrevista realizada en 2007 por Renaud Persiaux 
